\title{
Comparison of the aerosol optical properties and size distribution retrieved by sun photometer with in situ measurements at midlatitude
}

\author{
Aurélien Chauvigné ${ }^{1}$, Karine Sellegri ${ }^{1}$, Maxime Hervo ${ }^{1,2}$, Nadège Montoux ${ }^{1}$, Patrick Freville $^{1}$, and Philippe Goloub ${ }^{3}$ \\ ${ }^{1}$ Laboratoire de Météorologie Physique, OPGC, CNRS, Université Blaise Pascal, BP 10448, 63000 Clermont-Ferrand, France \\ ${ }^{2}$ Federal Office of Meteorology and Climatology MeteoSwiss, Payerne, Switzerland \\ ${ }^{3}$ Laboratoire d'Optique Atmosphérique, Université des Sciences et Techniques de Lille, Villeneuve d'Ascq, France
}

Correspondence to: Karine Sellegri (k.sellegri@opgc.univ-bpclermont.fr)

Received: 25 March 2016 - Published in Atmos. Meas. Tech. Discuss.: 9 May 2016

Revised: 31 August 2016 - Accepted: 1 September 2016 - Published: 16 September 2016

\begin{abstract}
Aerosols influence the Earth radiative budget through scattering and absorption of solar radiation. Several methods are used to investigate aerosol properties and thus quantify their direct and indirect impacts on climate. At the Puy de Dôme station, continuous high-altitude near-surface in situ measurements and low-altitude ground-based remote sensing atmospheric column measurements give the opportunity to compare the aerosol extinction measured with both methods over a 1-year period. To our knowledge, it is the first time that such a comparison is realised with continuous measurements of a high-altitude site during a long-term period. This comparison addresses to which extent near-surface in situ measurements are representative of the whole atmospheric column, the aerosol mixing layer (ML) or the free troposphere (FT). In particular, the impact of multi-aerosol layers events detected using lidar backscatter profiles is analysed. A good correlation between in situ aerosol extinction coefficient and aerosol optical depth (AOD) measured by the Aerosol Robotic Network (AERONET) sun photometer is observed with a correlation coefficient around 0.80 , indicating that the in situ measurements station is representative of the overall atmospheric column. After filtering for multilayer cases and correcting for each layer optical contribution (ML and FT), the atmospheric structure seems to be the main factor influencing the comparison between the two measurement techniques. When the site lies in the ML, the in situ extinction represents $45 \%$ of the sun photometer ML extinction while when the site lies within the FT, the in situ extinction is more than 2 times higher than the FT sun photometer extinction. Moreover, the assumption of a decreasing
\end{abstract}

linear vertical aerosol profile in the whole atmosphere has been tested, significantly improving the instrumental agreement. Remote sensing retrievals of the aerosol particle size distributions (PSDs) from the sun photometer observations are then compared to the near-surface in situ measurements, at dry and at ambient relative humidities. When in situ measurements are considered at dry state, the in situ fine mode diameters are $44 \%$ higher than the sun-photometer-retrieved diameters and in situ volume concentrations are $20 \%$ lower than those of the sun-photometer-retrieved fine mode concentration. Using a parameterised hygroscopic growth factor applied to aerosol diameters, the difference between in situ and retrieved diameters grows larger. Coarse mode in situ diameters and concentrations show a good correlation with retrieved PSDs from remote sensing.

\section{Introduction}

Over the last decade, aerosol studies have increased significantly due to the large uncertainty associated with their impact on climate in global models (IPCC, 2013). The important variability of aerosol size, concentration and composition partly drive this uncertainty on their direct and indirect radiative effects (Nemesure et al., 1995; Boucher and Anderson, 1995; Pilinis and Li, 1998). Boucher and Anderson (1995) calculated that aerosol radiative forcing is more sensitive to small particles (geometric volume mean diameter less than $0.2 \mu \mathrm{m}$ ) and that variations on particle size and 
composition can influence the aerosol direct radiative forcing by around $20 \%$. Another important parameter that is not included well in radiative models is the humidity effect on aerosol properties. Pilinis et al. (1995) estimated from a box model an increase of the aerosol radiative forcing by a factor of 2.1 for a relative humidity $(\mathrm{RH})$ varying from 40 to $80 \%$. Hervo et al. (2014) showed important hygroscopic enhancement of aerosol optical properties at Puy de Dôme station (PUY) according different air mass origins over a 2-year period.

Both horizontal and vertical aerosol distributions determine the magnitude of the direct and indirect radiative effects and are still limits for general aerosol studies (Laj et al., 2009). The aerosol concentration is typically higher within the low tropospheric layer (mixing layer, ML) than in the free troposphere (FT), but aerosol layers such as desert dust, marine aerosol or volcanic ash can also be transported at high altitude above the ML over large distances. Hence, ground-based measurements are not always representative of the whole atmospheric column and the atmospheric structure is an important parameter to take into account for aerosol studies. Several measurement techniques are available for characterising the aerosol properties and their vertical distribution in the atmospheric column. The Aerosol Robotic Network (AERONET; Holben et al., 1998), initiated by NASA's EOS, provides ground-based remote sensing aerosol measurements to follow the long-term aerosol properties such as optical, microphysical and radiative properties integrated over the whole atmospheric column at ambient conditions. Dubovik and King (2000) performed sensitivity studies on the AERONET retrievals, showing difficulties to retrieve complex aerosol properties such as the single scattering albedo or the aerosol refractive index when the aerosol optical depth is low $(\mathrm{AOD}<0.2)$ but demonstrates that particle size distribution (PSD) are well retrieved for AOD higher than 0.05 . For AOD ranging between 0.05 and 1.0, they calculate that an error of \pm 0.01 on direct AOD measurement at $440 \mathrm{~nm}$ can generate an error on sun photometer volume concentration retrievals between 15 and $35 \%$ between $0.1 \mu \mathrm{m}$ and $7 \mu \mathrm{m}$ and between 30 and $100 \%$ out of this range.

In situ measurements provide a large data set of aerosol properties: size distributions over a large size range, chemical composition, hygroscopic properties and optical properties. However, in situ measurements performed from groundbased stations provide aerosol properties at a single point of the atmosphere, often under dry conditions. Boyouk et al. (2010) studied the bias between ground-level aerosol mass concentrations and aerosol mass concentrations retrieved from both satellites and a sun photometer during a 12-day period in Lille, France. Results show in situ $\mathrm{PM}_{2.5}$ measurements $20 \%$ higher than the retrieved PM2.5 from sun photometer and a correlation coefficient of 0.56 between the two measurement techniques. The authors highlight the fact that taking into account the inhomogeneity of the atmosphere can significantly improve the correlation between ground- level in situ measurements and remote sensing retrievals. They show that correcting the sun photometer retrievals by the ML height decreases the discrepancy between measurements by about $10 \%$. Bergin et al. (2000) also highlighted the importance of taking into account the ML height into the comparison of in situ ground-based (Southern Great Plains, Oklahoma; $320 \mathrm{~m}$ a.s.l.) measurements (20 cloud-free measurements) and remote sensing extinction coefficients (from $r^{2}=0.55$ to $\left.r^{2}=0.78\right)$ using a 1 -year period data set. The authors found integrated in situ AOD $70 \%$ lower than sun photometer AOD in dry condition and $40 \%$ lower when taking into account hygroscopic growth factor (HGF) on extinction coefficient. The aerosol extinction coefficient distribution along the atmospheric column has also been investigated by Schmid et al. $(2003,2006,2009)$ during several experiments at different locations (ACE-Asia in Japan, ARM AIOP (Ferrare et al., 2006) and ARM ALIVE in Oklahoma) with an airborne sun photometer (AATS-14), integrated airborne in situ measurements and lidars (Raman lidar and micropulse lidars). The experiments are based on the comparison of 19 flights during ACE-Asia program (April 2001), 16 flights during AIOP campaign (May 2003) and 12 flights during ALIVE campaign (September 2005). All studies report in situ extinction coefficients lower than retrieved sun photometer extinction coefficients (between 11 and $17 \%$ lower) and higher than lidar measurements (between 13 and 54\% higher). Authors mainly explain the discrepancies between measurements methods by humidity effects, by largest particles losses from in situ probes and by the correction of aerosol vertical distribution in lidar profiles (mainly due to overlap correction).

A similar comparison performed during dust cases over Morocco revealed similar discrepancies, with the in situ (airborne measurements) AOD being around 20\% lower than sun photometer direct measurements at a wavelength of $500 \mathrm{~nm}$ from three different flights (Müller et al., 2012). However, the authors highlight significant uncertainties in aerosol properties retrievals from sun photometers which propagate to climate forcing modelling, especially when the atmosphere is inhomogeneous. Molero et al. (2012) studied aerosol size distribution from ground-based in situ measurements and sun photometer retrievals from a 3-week campaign, also using lidar measurements (SPALI10 in Spain in 2010). Results show a disagreement between volume concentrations measured from the two techniques but a wellretrieved shape of the accumulation and coarse modes. Authors explain this discrepancy with the non-homogeneous atmosphere during the comparison, in agreement with the conclusions from Müller et al. (2012).

Several other studies used aircraft in situ measurements in order to describe the entire atmospheric column during specific research campaigns (ACE-Asia, ACE-2, SAFARI 2000, etc.) in comparison to remote sensing measurements performed at the same time. General results agree that aircraft vertical profiles are well correlated to sun photometer mea- 
surements (Haywood et al., 2003; Magi et al., 2007; Johnson et al., 2008). However, some features can influence the correlation. Haywood et al. (2003) showed that aircraft pitch can influence in situ measurements and data need to be corrected either during the ascent or the descent. Despite a good correlation between in situ and sun photometer AOD measurements, authors highlighted that in situ measurements overestimate extinction measurements (around $25 \%$ ) in opposition to Müller et al. (2012) and Schmid et al. (2003). Magi et al. (2007) indicated that the particle shape and wavelength measurement can significantly influence both remote sensing and in situ measurements. Johnson et al. (2008) reported good correlation but an important factor (up to a factor of 2 in absolute value) between ground-based remote sensing and in situ aircraft measurements mainly due to distance between the two measurement techniques (up to $100 \mathrm{~km}$ ). On average, authors reported aircraft AOD $30 \%$ under AERONET measurements at $550 \mathrm{~nm}$, also shown by Osborne et al. (2008). The PSDs are well correlated between sun photometer and aircraft measurements between 0.05 and $1 \mu \mathrm{m}$ (Haywood et al., 2003). However, the PSDs can also be biased vertical heterogeneity of the atmosphere and measurements synchronisation between different sampling methods (Osborne and Haywood, 2005). The particle hygroscopicity also has an important influence on aerosol properties and hence on the comparison between measurement techniques. Carrico et al. (2003) highlighted the impact of ambient RH on aerosol optical properties for different aerosol natures and from aircraft measurement during ACE-Asia experiment. The ratio between ambient scattering property and the dry measurement $(\mathrm{RH}=19 \%)$ from in situ probes vary from 1 to 1.6 from dust to marine aerosols, which is of the order of magnitude of the discrepancy between in situ and remote sensing measurements in the literature. To our knowledge, comparisons between ground-based in situ measurements and remote sensing retrievals have not yet been performed from high-altitude sites over long-term periods. In the present paper, we compare the extinction coefficients and PSD retrievals from a low-altitude sun photometer with the same aerosol variables measured in situ at a nearby high-altitude station, using the information on the atmospheric structure from a co-located lidar. We investigate the impact of the atmospheric structure and of the aerosol hygroscopicity on the agreement between the in situ and remote sensing measurement techniques.

\section{Site and instrumental description}

The PUY atmospheric station is located in central France $\left(45^{\circ} 46 \mathrm{~N}, 2^{\circ} 57 \mathrm{E}\right)$ and composed of a high-altitude site (at the top of the Puy de Dôme, $1465 \mathrm{~m}$ a.s.l.) and a low-altitude site (Cezeaux, $410 \mathrm{~m}$ a.s.l.). It is part of the global GAW (Global Atmospheric Watch) network and one of the 43 ACTRIS (Aerosol, Cloud and Trace gases Research Infrastructure Network) stations for monitoring climate-relevant atmo- spheric variables. Meteorological parameters (temperature, $\mathrm{RH}$, wind speed and direction) are continuously monitored at both sites (Puy de Dôme and Cezeaux). At the PUY station, a large data set of parameters of the gas phase $\left(\mathrm{O}_{3}, \mathrm{CO}, \mathrm{CO}_{2}\right.$, $\mathrm{NO}, \mathrm{NO}_{2}, \mathrm{CH}_{4}, \mathrm{~N}_{2} \mathrm{O}, \mathrm{SF}_{6}$, volatile organic compounds, $\mathrm{Rd}$ ) and of the particulate phase (scattering, absorption, elemental and organic carbon (EC/OC) on filter, inorganic ions on filter, condensation nuclei $(\mathrm{CN})>10 \mathrm{~nm}, \mathrm{CN}>1.2 \mathrm{~nm}$, size distribution of nucleation mode $(2-40 \mathrm{~nm})$, size distribution of fine mode $(10-400 \mathrm{~nm})$, size distribution of coarse mode $(0.5-$ 10 microns), $\mathrm{PM}_{10}$ and cloud condensation nuclei (CCN) size distribution) is continuously monitored. Previous work shows that the station is representative of the regional background (Asmi et al., 2011; Henne et al., 2010). The PUY is located on the first mountain chain facing dominant western winds. It is one of the highest points of the Chaîne des Puys, which comprises 80 volcanoes aligned north to south on a 3 to $5 \mathrm{~km}$ wide strip of land, a little over $45 \mathrm{~km}$ in length. This configuration induces less modifications of the general airflow than in larger mountain chains such as the Alps in Europe. Indeed, this feature leads to a quasi-absence of valley winds, observed in more complex topographies, and permits the sampling of air masses often representative of the altitude at which the station is located. the Cézeaux University Campus site $\left(\mathrm{CZ}, 45^{\circ} 45 \mathrm{~N}, 3^{\circ} 6 \mathrm{E} ; 410 \mathrm{~m}\right.$ a.s.l. $), 11 \mathrm{~km}$ east of and $1055 \mathrm{~m}$ below the Puy de Dôme, houses remote sensing measurements that give information on the structure and properties of aerosol layers along the atmospheric column. The PUY station is one of the very few high-altitude stations worldwide measuring a complete set of in situ measurements of the gas and particulate phases, coupled with nearly colocated lidar and sun photometer measurements at its base.

\subsection{In situ aerosol measurements at the PUY station}

Aerosol particles are sampled through a temperaturecontrolled whole air inlet, the size cut of which is 35 micron under the average $6 \mathrm{~m} \mathrm{~s}^{-1}$ wind speed conditions. A gradient between ambient and room temperatures ensures that the $\mathrm{RH}$ monitored at the inlet of the instruments does not exceed 40 and that the aerosol is characterized at its dry state.

Aerosol PSDs are characterized with a combination of a scanning mobility particle sizer (SMPS; Venzac et al., 2009) and an optical particle counter (OPC; Grimm 1.108 in 2011), covering the diameter range of $10-400 \mathrm{~nm}$ and $350 \mathrm{~nm}-$ $18 \mu \mathrm{m}$ respectively with a total of 118 bins. The SMPS, developed at the Laboratoire de Météorologie Physique (LaMP) at Clermont-Ferrand, is composed of a neutralising device, a differential mobility analyser (DMA) operating in a closed dried loop and a condensation particle counter (CPC). The SMPS is based on the scanning mobility measurement concept introduced by Wang and Flagan (1990). The OPC operates with a laser beam at $638 \mathrm{~nm}$ crossing a particle chamber and retrieving the PSD from the diffused light (Burkart et al., 2010). Both instruments reveal uncertainties 
in number concentrations around $10 \%$ (Venzac et al., 2009; Burkart et al., 2010) mainly due to the flow rate, the cut-off diameters and the CPC counting efficiency.

Aerosol light absorption $\left(\sigma_{\text {abs }}\right)$ and scattering $\left(\sigma_{\text {scat }}\right)$ coefficients are measured using a multi-angle absorption photometer (MAAP 5012, 670 nm) and a three wavelengths (450, 550 and $700 \mathrm{~nm}$ ) nephelometer (TSI 3563) respectively. The MAAP instrument measures the radiation transmitted and scattered back from a particle-loaded fiber filter to retrieve an absorption coefficient (Petzold and Schönlinner, 2004). The nephelometer measures the integrated light scattered by particles from 7 to $170^{\circ}$ and from 90 to $170^{\circ}$. Nephelometer data are corrected for detection limits and truncation errors according to Anderson and Ogren (1998). The Ångström coefficient (å) is computed from multi-wavelength nephelometer measurements according Eq. (1). This Ångström coefficient is used to compare all instruments at the same wavelength. In this study, the $675 \mathrm{~nm}$ channel corresponding to a sun photometer wavelength is selected, $5 \mathrm{~nm}$ apart from MAAP measurements wavelength $\left(\lambda_{0}=670 \mathrm{~nm}\right)$ and $25 \mathrm{~nm}$ from the nephelometer measurements wavelength $\left(\lambda_{0}=700 \mathrm{~nm}\right)$. Hence, the in situ extinction coefficient $\left(\mathrm{Ext}_{\mathrm{IS}}\right)$ and aerosol single scattering albedo $\left(\omega_{0}\right)$ are calculated at $\lambda=675 \mathrm{~nm}$ according to Eqs. (2) and (3).

$$
\begin{aligned}
& \frac{\sigma_{\text {scat }}(\lambda)}{\sigma_{\text {scat }}\left(\lambda_{0}\right)}=\left(\frac{\lambda}{\lambda_{0}}\right)^{-\mathrm{a}} \\
& \operatorname{Ext}_{\text {IS }}(\lambda)=\sigma_{\text {abs }}(\lambda)+\sigma_{\text {scat }}(\lambda) \\
& \omega_{0}(\lambda)=\frac{\sigma_{\text {scat }}(\lambda)}{\sigma_{\text {scat }}(\lambda)+\sigma_{\text {abs }}(\lambda)}
\end{aligned}
$$

Uncertainties were previously reported for nephelometer and MAAP measurements were in the range of 1 to $5 \%$ due to truncation and angular non-idealities in the light source (Anderson et al., 1996 and Bond et al., 2009) and around $12 \%$ for MAAP measurements (Petzold and Schönlinner, 2004).

\subsection{Remote sensing measurements at Cézeaux site}

A CIMEL sun photometer (CE-318), operating at the CZ site, measures the aerosol optical properties of the total integrated atmospheric column under ambient conditions at four wavelengths $(440,675,870$ and $1020 \mathrm{~nm})$. The instrument is part of AERONET (Holben et al., 1998). Data are automatically sent to the Laboratoire d'Optique Atmospherique (LOA at Lille) for processing and full inversion data are available on the AERONET website. Direct sun photometer measurements provide the column-averaged AOD and Ångström exponent. Additionally, an inversion algorithm described by Dubovik and King (2000) is used to retrieve the particle volume size distribution on the 0.10 to $30 \mu \mathrm{m}$ diameter range. Due to Dubovik's algorithm, AOD and inverted properties can be retrieved at the same wavelengths. Depending on the instrument, the measurements can be taken on all or some of the following channels: $340,380,440,500,675,870,1020$ and $1640 \mathrm{~nm}$. The version 2 and level 1.5 of AERONET data are used in this study corresponding to automatically cloudfiltered data. The aerosol PSD retrieved from the sun photometer measurements is meanly separated into two modes, a fine mode (particles $<0.6 \mu \mathrm{m}$ ) and a coarse mode (particles $>0.6 \mu \mathrm{m}$ ) with a possible intermediate mode (Kaufman and Holben, 1996). A discussion on errors of the data products can be found in Dubovik et al. (2000).

A lidar provides information on the vertical profile of aerosol particle properties continuously. The lidar operated at $\mathrm{CZ}$ is a Raymetrics system with a laser emitting a polarised light at $355 \mathrm{~nm}$ and a telescope of $40 \mathrm{~cm}$ diameter collecting the light backscattered by molecules and aerosols. An optical box allows us to separate the Rayleigh-Mie signal at $355 \mathrm{~nm}$ in two perpendicular polarised directions and the Raman signals due to nitrogen $(387 \mathrm{~nm})$ and water vapour $(408 \mathrm{~nm})$. The minimum time resolution of one profile is $1 \mathrm{~min}$ and the vertical resolution is $7.5 \mathrm{~m}$. The measurements follow the procedures of the European Aerosol Research Lidar Network (EARLINET). For the present study, a Klett inversion (Klett, 1985) is used to retrieve elastic aerosol backscatter profiles with a constant lidar ratio of $58 \mathrm{sr}$ (Müller et al., 2007), corresponding to a mean central European air mass lidar ratio at $355 \mathrm{~nm}$. A more detailed description of this instrument and of the data inversion is available in Hervo et al. (2012) and Freville et al. (2015). In this study, the lidar profiles are mainly used to detect multiple aerosol layers and to evaluate the optical contribution of aerosols in the different atmospheric layers (ML and FT). In order to correct the blind zone between the laser beam and the field of view of the telescope, a theoretical overlap (Kuze et al., 1998) is applied to lidar measurements from the ground to the altitude of full overlap. Tests on this theoretical overlap were performed by comparing the altitude of the range-corrected lidar signal maximum $\left(P r_{\max }^{2}\right)$ with the theoretical altitude of full overlap retrieved using the telecover technique. The comparison between $\operatorname{Pr}_{\max }^{2}$ and the full overlap altitude gives a correlation coefficient $\left(r^{2}\right)$ of 0.997 and with a slope close to 1 . This permits to make a good estimation of the full overlap altitude only by the knowledge of the $P r_{\max }^{2}$.

\section{Data analysis}

In the present study, the aerosol PSDs obtained from in situ measurements and columnar remote sensing measurements are compared. The SMPS PSD can be fitted with a sum of log-normal modes to retrieve nucleation, Aitken and accumulation modes. However, for the purpose of comparison to the size distribution retrieved from the sun photometer, we chose to fit the SMPS size distribution with a single submicron mode, while the supermicron mode is fitted on the measured OPC PSD (Fig. 1). The sun photometer PSD is converted from $\mu \mathrm{m}^{3} \mathrm{~cm}^{-2}$ to $\mu \mathrm{m}^{3} \mathrm{~cm}^{-3}$ by dividing concentrations by the ML height from lidar measurements. The two 


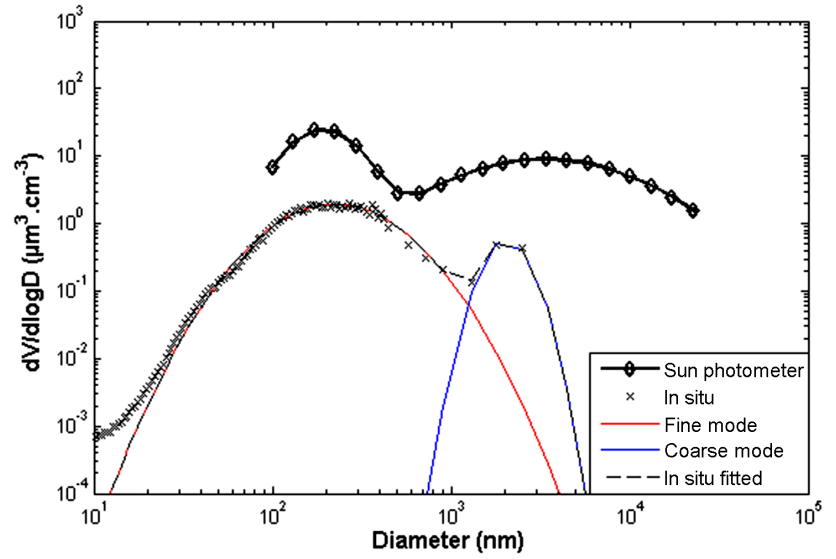

Figure 1. Volume particle size distribution from both in situ (cross) and sun photometer (bold line) measurements for 7 February 2011 at 11:03. In situ measurements (SMPS and OPC) are fit according to two modes, one fine mode (red line) and one coarse mode (blue line). The dashed black line is the sum of the two in situ modes.

modes from the two different instruments are considered separately in order to increase the number of cases available for comparison. The dry PSD is then corrected to ambient humidity using a HGF parameterisation.

Hervo et al. (2014) showed at the PUY station a strong impact of hygroscopicity on aerosol optical properties depending on air mass origin and season. In this study, in order to take into account the humidity effect on aerosol properties, the HGF is applied to dry in situ diameters in order to retrieve wet concentrations for each mode. A seasonally segregated parameterization (Holmgren et al., 2014) initialised at PUY station is used to apply an average HGF to the measured in situ dry PSD. As the Puy de Dôme and Cézeaux stations are separated by 11 and $1 \mathrm{~km}$ of altitude difference, a mean RH between the two sites is used in the parameterisation. Because the parameterisation is not well adapted for particles smaller than $30 \mathrm{~nm}$ and higher than $420 \mathrm{~nm}$, a HGF of 1 is taken for small particles $(<30 \mathrm{~nm})$ and the HGF at $420 \mathrm{~nm}$ is applied to higher particles (Rose et al., 2013). The wet distribution is then fitted to retrieve wet concentrations and mean diameters for the two modes.

The comparison of the in situ and remote sensing aerosol properties is strongly dependent on the atmospheric structure and layering. Hence, the STRAT (Structure of the Atmosphere) algorithm (Morille et al., 2007) is applied to the lidar measurements to identify atmospheric structure as cloud, molecular and aerosol layers as well as to give information on noise detection. The ML height is retrieved using the wavelet covariance technique (WCT; Brooks, 2003; Baars et al., 2008; Hervo et al., 2014) on the range-corrected lidar signal.

The diurnal variation of the ML is driven by surface heating. Depending of the time of the day and seasons, the ML limit can be above (ML cases) or below (FT cases) the PUY station altitude (1465 $\mathrm{m}$ a.s.l.). The PUY station was calculated using the ECMWF model to be in the ML usually during daytime and the warm seasons (spring and summer) and in the FT during nighttime during the cold seasons (autumn and winter) (Venzac et al., 2009). These variations were confirmed in the present study when using the lidar profiles. Because the sun photometer measures integrated aerosol properties and the PUY station is either in FT conditions or in ML conditions, it is necessary to separate optical contributions of ML and FT from the sun photometer signal. Using the ML height obtained from the lidar backscatter profile $(\beta)$, the fraction of aerosols from the ML that contributes to the total aerosol signal (over the whole atmospheric column) is calculated. In the present study, ML contribution $\left(R_{\mathrm{ML}}\right)$ is calculated from lidar backscatter $(\beta)$ according Eq. (4) and permits to separate both ML and FT properties from the sun photometer signals according Eqs. (5) and (6).

$$
\begin{aligned}
& R_{\mathrm{ML}}=\frac{\beta_{\mathrm{ML}}}{\beta_{\text {column }}}, \\
& \mathrm{AOD}_{\mathrm{ML}}=\mathrm{AOD}_{\mathrm{TOTAL}} \times R_{\mathrm{ML}}, \\
& \mathrm{AOD}_{\mathrm{FT}}=\mathrm{AOD}_{\mathrm{TOTAL}} \times\left(1-R_{\mathrm{ML}}\right),
\end{aligned}
$$

where $\beta_{\mathrm{ML}}$ is the lidar backscatter coefficient integrated from the ground level to the ML height. $B_{\text {column }}$ is the lidar backscatter coefficient integrated from the ground to an upper altitude of $5 \mathrm{~km}$, above which it is assumed that the aerosol contribution to the total backscatter is negligible (Nicolas et al., 2016). This fraction is then applied to the total AOD measured by the sun photometer (AOD $\mathrm{AOTAL}_{\text {TO }}$ ) to calculate the AOD of the ML ( $\mathrm{AOD}_{\mathrm{ML}}$ ) (Eq. 5) and the AOD of the FT (AOD FT) (Eq. 6).

Figure 2 shows an example of aerosol backscatter time series from lidar measurements, ML height and $R_{\mathrm{ML}} 29$ September 2011. In the top panel, green and black points show possible lidar signal inversion and missing data respectively. The dotted black line in both panels represents the altitude of the PUY station. For this case, ML height varies from $1200 \mathrm{~m}$ a.s.l. during nighttime to $1500 \mathrm{~m}$ a.s.l. during daytime corresponding to a small heat convection (autumn case). On this day, the ML contribution shows a diurnal variation with a maximum during daytime, showing that aerosol sources increase during daytime and are not fully compensated by dilution when the ML extends. For this typical case, the ML contribution varies from $60 \%$ at night to $78 \%$ shortly after noon (UTC) in agreement with previous results. Ricchiazzi et al. (2006) found ML contributions between 45 and $90 \%$ using airborne photometer (AATS-14) profiles during 4 cloudfree days and ML contributions between 19 and $72 \%$ (mean of $44 \%$ ) are found by Bergin et al. (2000) using a lidar profile technique. 


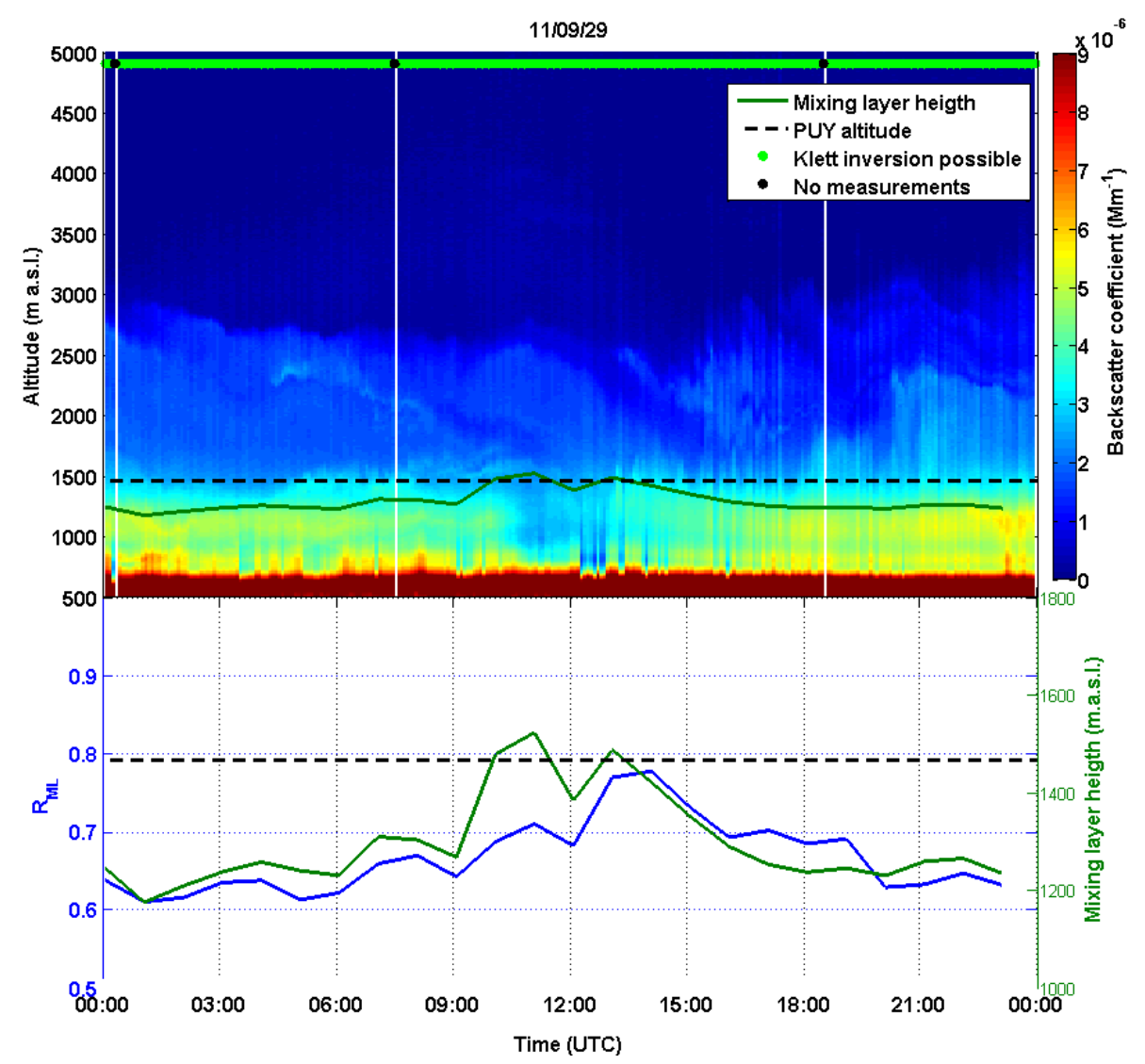

Figure 2. Top: aerosol backscatter time series (UTC) on 29 September 2011 from lidar measurements performed at CZ with a 5 min resolution. Green points at the top of the figure indicate measurements with possible inversion and black points indicate no lidar measurements. Black dashed lines represent the Puy de Dôme top. Bottom: mixing layer height (green line) from WCT algorithm and mixing layer contribution $\left(R_{\mathrm{ML}}\right)$ (blue line).

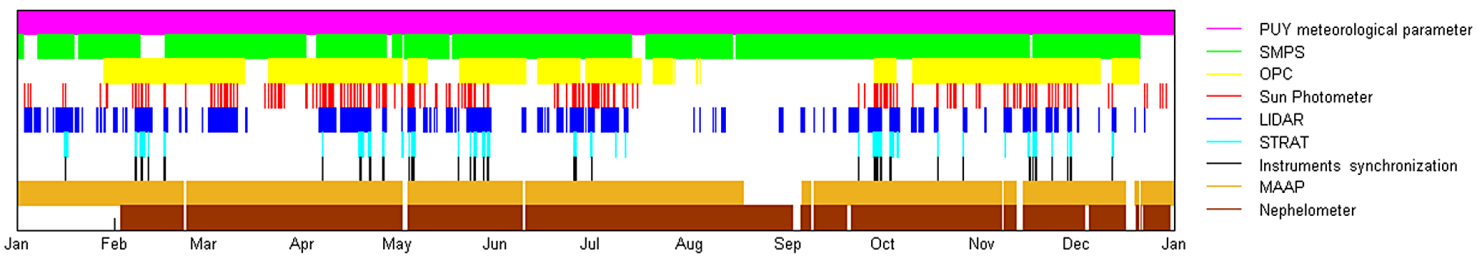

Figure 3. Temporal series of available instruments and cloud screening from RH information during the year 2011. Magenta, green, yellow, red, blue, orange and brown areas represent meteorological parameters at PUY station, SMPS, OPC-GRIMM, sun photometer, lidar, MAAP and nephelometer date. The cyan area shows STRAT selection from lidar analysis and the black area gives selected points for this study.

\section{Data set used}

Long-term data sets present the advantage of offering a large variability of statistically reliable environmental cases and allow us to investigate contrasts between seasons, time of the day, meteorological conditions or air mass types. In this study, we focus on the year 2011 that offers a large availability of simultaneous measurements. Figure 3 shows the availability time series of each instrument needed for this study (lidar, sun photometer, SMPS or OPC, MAAP, nephelometer and meteorological parameters) over the 2011 period. In situ RH above $95 \%$ is used as a cloud screening, in addition to the cloud classification derived from the STRAT algorithm applied to the lidar measurements. Despite the need of a large amount of instruments operating simultaneously under clear sky conditions, $3571 \mathrm{~h}$ data points can be used for extinction comparisons and $1161 \mathrm{~h}$ data points if multilayer cases are excluded using STRAT. For PSD comparisons, $4121 \mathrm{~h}$ data points are available and 155 data points (black in Fig. 3) if multilayer cases are excluded using STRAT. Among these 

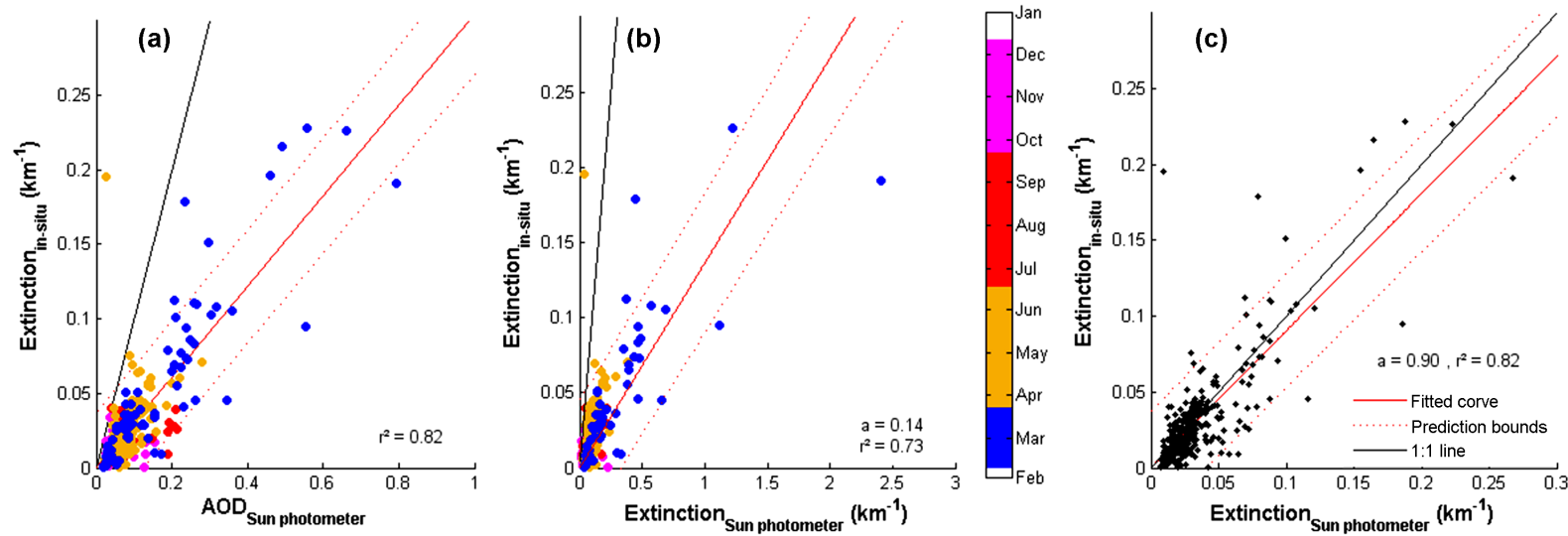

Figure 4. In situ extinction coefficient at $675 \mathrm{~nm}$ calculated from nephelometer and MAAP measurements vs. (a) sun photometer AOD and (b) sun photometer extinction $\left(\mathrm{km}^{-1}\right)$ colour-coded by season. (c) Same comparison of extinction coefficients using linear aerosol vertical decreasing assumption. Full and dashed red lines correspond to the fitted line and prediction bounds respectively and the black line to the $1: 1$ line.

155 data points, 92 include SMPS size distributions and 80 include OPC-GRIMM size distribution.

No OPC-GRIMM measurements have been acquired on January and from August to September, and an important gap is observed in August and September due to sun photometer issues. Despite this lack of data, all season can be represented in this study with a significant number of cases as shown in Fig. 4.

\section{Results}

\subsection{AOD and aerosol extinction}

\subsubsection{Cloud-free conditions}

A first comparison of direct measurements of the aerosol in situ extinction and remote sensing (sun photometer) AOD can be performed. For this comparison, we selected cloudfree measurements which represent 357 data points.

Figure 4a shows the relationship between the aerosol extinction measured from in situ probes at dry state and the AOD measured by the sun photometer according the season at $675 \mathrm{~nm}$. Only few points during summer 2011 are taken into account due to instrumental issues (43 points during summer, 80 during autumn, 86 during winter and 148 during spring). Although the AOD is integrated over the whole atmospheric column while the aerosol in situ extinction is measured at one single altitude, they are strongly correlated $\left(r^{2}=0.82\right)$, indicating that the intermediate altitude of $1465 \mathrm{~m}$, often at the interface between the ML and the FT where in situ measurements are performed is overall representative of the whole atmospheric column. The small dispersion of the comparison can be due to instruments uncertainties estimate around $5 \%$ for in situ measurements (Bond et al., 2009) and 0.02 for sun photometer AOD (Dubovik and King, 2000). However, this result shows a better cor- relation between measurement techniques than the correlation reported in previous works $\left(r^{2}=0.55\right.$ between sun photometer AOD and ground-based in situ extinction coefficient according to Bergin et al., 2000). This result might be explained by a better representativeness of the atmospheric column by high-altitude in situ measurements, usually representative of a large spatial area (Henne et al., 2010) and less affected by eventual local contaminations than groundbased low-altitude sites might be. No clear difference is observed between seasons. In order to quantitatively compare aerosol extinctions measured by in situ and remote sensing techniques, a first approximation is to assume that most of the sun photometer signal is due to aerosols present in the ML. Hence, we calculate the average aerosol extinction as the AOD contained in the ML following:

$\mathrm{Ext}_{\text {sun photometer }}=\frac{\mathrm{AOD}_{\text {sun photometer }}}{\text { ML height }}$.

where ML height is obtained from the lidar data.

Figure $4 \mathrm{~b}$ shows the aerosol extinction coefficient measured from in situ instruments as a function of the sun photometer aerosol extinction coefficient derived from Eq. (7). The in situ aerosol extinction coefficients are still highly correlated with the sun photometer extinction coefficient $\left(r^{2}=0.73\right)$. This result is in a good agreement with those reported by Bergin et al. (2000) showing a correlation factor of 0.78 between in situ and sun photometer measurements. A lower correlation than with the total AOD can be attributed to the fact that, on one hand, the Puy de Dôme instruments sample not only the ML but also frequently the FT (as shown in Fig. 2, bottom) and, on the other hand, not all of the AOD is due to the ML. The in situ extinction is on average only $14 \%$ of the sun photometer extinction (12\% during winter, $17 \%$ during summer, $22 \%$ during autumn and $24 \%$ during spring). This is likely due to the fact that a number of in situ 


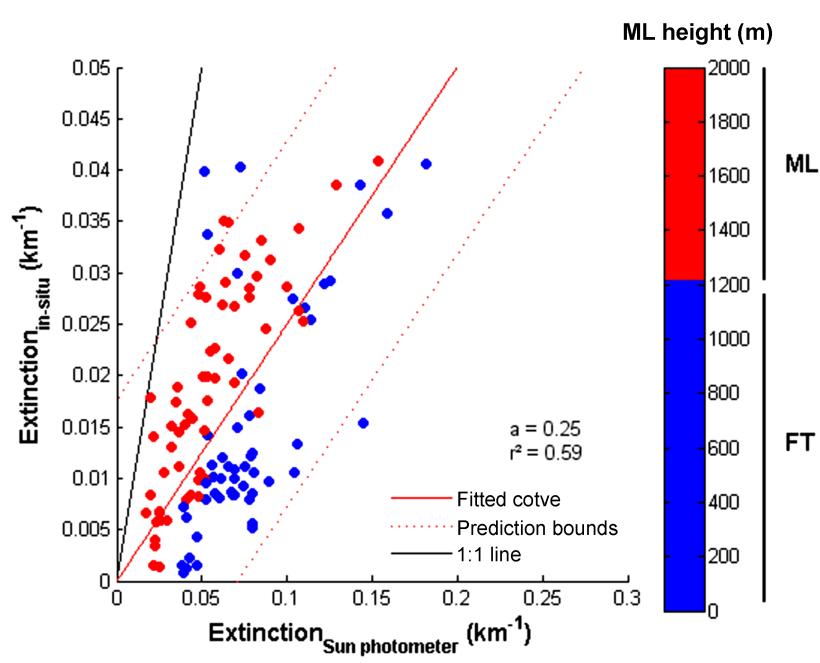

Figure 5. Scatter plot of in situ and sun photometer extinction coefficients at $675 \mathrm{~nm}$ after filtering the multilayer cases of high-altitude transport using STRAT algorithm coloured by the ML height (from WCT algorithm).

data are especially low because they are measured in FT conditions. Indeed, characterized by the lowest ML height, winter cases present the largest difference between the two measurement techniques. The assumption of homogeneous ML can also explain the significant difference between in situ and remote sensing measurements. A linear decreasing profile of the aerosol extinction with altitude has been calculated using two constrains:

- The extinction coefficient is equal to zero at $5 \mathrm{~km}$ high.

- The integration of vertical extinction is equal to the sun photometer AOD.

The sun photometer extinction is then retrieved from the linear equation at $1465 \mathrm{~m}$. Results show better agreement between the two measurement techniques (Fig. 4c). However, several recent studies use the assumption of an homogeneous ML and others observe dry extinction roughly independent of altitude (Kanitz et al., 2013; Wagner et al., 2015). The Sheridan et al. (2012) study, based on several aerosol profile measurements (aircraft in situ, ground-based remote sensing and from space), shows that the ML can be well mixed. Hence, we also test the hypothesis of a constant aerosol profile within the ML. Moreover, other bias between the two measurements may be due to the fact that on some occasions such as during dust episodes, high concentrations of aerosols are preferentially transported at high altitudes, as evidenced in Bourcier et al. (2011). In some cases, dust or sea salt aerosols may be transported above the PUY station and hence captured by the sun photometer but not detected by the PUY in situ instrumentation.

\subsubsection{Impact of a multilayer atmosphere}

In order to exclude such cases of multilayer aerosol transport, the STRAT algorithm was applied to filter them out from the database. After filtering the multilayer cases, only 116 cases (33\%) remain from the original data set. Due to this lower number of data points, the correlation between the in situ and sun photometer extinction is lower when multilayer cases are excluded $\left(r^{2}=0.59\right)$ (Fig. 5). Under these particular atmospheric conditions, the in situ extinction coefficient at the PUY station ranges from 0 to $0.04 \mathrm{~km}^{-1}$ while the sun photometer extinction ranges from 0 to $0.2 \mathrm{~km}^{-1}$. The sun photometer values higher than $0.2 \mathrm{~km}^{-1}$ observed in Fig. 4 but not in Fig. 5 were indeed due to heterogeneous cases, thus probably corresponding to dust or marine aerosol transported at higher altitudes than the PUY station. As these points corresponding to multilayer cases were still well correlated, it is likely that the Puy de Dôme in situ measurements capture high-altitude aerosol transport events, but at a diluted concentration. After multilayer filtering, the in situ extinction is closer to the extinction from the sun photometer $(25 \%$ of the sun photometer extinction compared to $14 \%$ before multilayer filtering).

The second likely explanation for measuring a lower extinction from in situ instruments compared to remote sensing average is the fact that the PUY station samples in a less-concentrated aerosol layer (FT) part of the time. This is evidenced in situ extinction measurements are colour-coded according to whether they belong to the ML or to the FT (Fig. 5). A threshold at $1200 \mathrm{~m}$ a.s.l. is taken for ML conditions at PUY station in order to take into consideration the impact of forced convection due to topographic effects (Venzac et al., 2009). The results clearly show different correlations between extinction coefficients when in situ measurements are performed in the ML (in red, WCT $>1200 \mathrm{~m}$ ) and when they are performed in the FT (in blue, WCT $<1200 \mathrm{~m}$ ). In FT conditions, in situ measurements are mainly lower than the overall fitted line and, in ML conditions, in situ measurements are mainly higher (33\% of the sun photometer measurements in ML conditions and $20 \%$ in FT conditions). Correlations under ML conditions show very close similarities to some previous studies (30\% discrepancy reported from Johnson et al. (2008) and Osborne et al. (2008) from aircraft measurements during DABEX experiments).

\subsubsection{Impact of the layer contributions}

When the PUY site is in the ML (WCT > 1200), the fraction of the sun photometer AOD comprised in the ML (Eq. 5) was calculated by using the ratio of ML/total backscatter measured by lidar following Eq. (4) (Sect. 3). Using the same method, when the Puy de Dôme in situ measurements are performed in the FT (WCT $<1200 \mathrm{~m}$ ), the corresponding fraction of the sun photometer AOD is calculated following Eq. (6). 
Results are shown in Fig. 6. A global analysis combining all data (ML and FT cases together) shows a net improvement of the agreement between measurements, with the sun photometer extinction being $49 \%$ lower than the in situ extinction. This discrepancy is still higher than the one previously reported in the literature between extinction coefficients measured by a sun photometer and in situ airborne probes, performed on case studies. Several studies found in situ measurements around $15 \%$ lower than remote sensing measurements (Schmid et al., 2003, 2009; Müller et al., 2012). Our results are not issued from in situ complete vertical profiles but rather from one single point measurements, which likely explains the different slopes and the higher discrepancy. In details, the 116 data points were separated between cases when the PUY station was located in the ML (63 data points, red fitted curve and circle markers) and when it was located in the FT (53 data points, blue fitted curve and cross markers) based on the WCT calculation from lidar measurements (Fig. 5). For ML cases, the sun photometer measurements are closer to in situ extinction than in the previous analysis (in situ extinction values represent $45 \%$ of the ML sun photometer extinction as opposed to $33 \%$ ). For FT cases, the in situ extinction is more than 2 times higher than the FT sun photometer extinction. These results are mainly explained by the presence of aerosol concentration gradients in both atmospheric layers, which are not fully mixed. In situ probes measure either in the upper part of the ML, where concentrations are not as high as at surface where sources of aerosols are located, or in the lower part of the FT, more influenced by the ML concentration than the upper FT. To summarise, when PUY station measurements are in ML conditions, optical properties would be underestimated compared to the mean ML and vice versa in FT conditions.

In comparison to the linear aerosol vertical decreasing model (Fig. 4c), the present results are still less correlated for both layers. Despite a number of studies using a homogeneous ML model (Sheridan et al., 2012; Kanitz et al., 2013; Wagner et al., 2015), the assumption of using linear decreasing of aerosol concentration from the ground to $5000 \mathrm{~m}$ a.s.l. seems to be in better agreement with the integrated sun photometer measurements. However, as mentioned by Andrews et al. (2011) study, a separate definition of ML and FT layers is more appropriate.

The comparison of extinctions in Fig. 6 is colour-coded by the mean RH between the two stations, which is a good tracer for ML height (Seidel et al., 2010). The goal was to examine whether an additional explanation for the in situ measurement being lower than the sun photometer data in the ML could be the amount of condensed water contributing to the aerosol extinction, which is not taken into account in the in situ measurements. We observe that even though FT air masses (cross marker in Fig. 6) are indeed overall dryer than ML air masses, in each atmospheric layer the high RH data points do not obviously correspond to dispersed data points. Although previous studies have shown an important role of

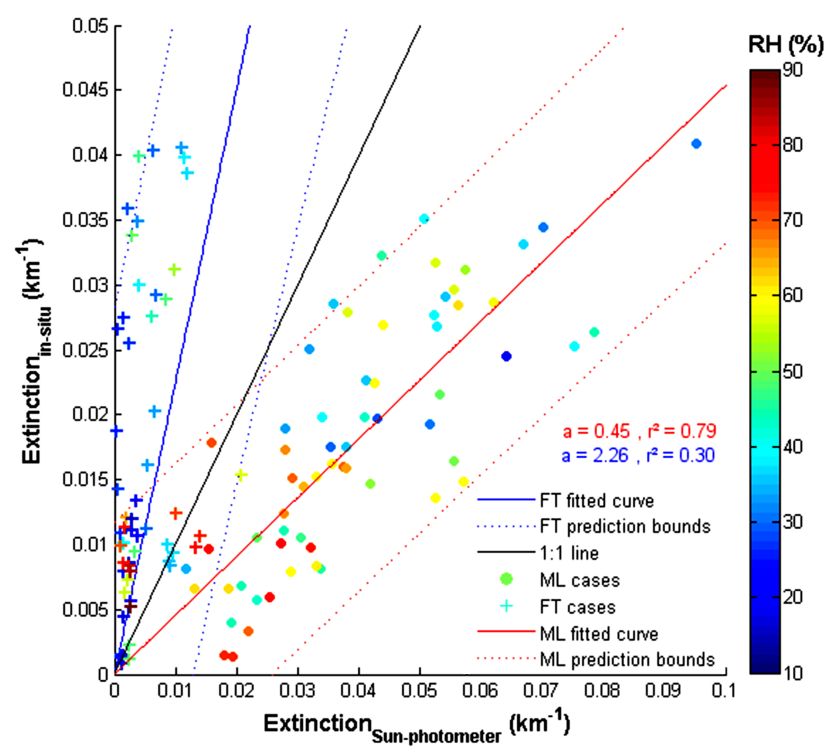

Figure 6. Scatter plot of in situ and sun photometer extinction coefficients at $675 \mathrm{~nm}$ after applying the mixing layer contribution factor to sun photometer measurements. Colours correspond to the mean relative humidity between the two sites. Blue fit and cross markers are for FT data and red fit and circle markers for ML data.

humidity in the comparison of in situ and remote sensing measurements (in reducing the discrepancy from 70 to $40 \%$; Bergin et al., 2000), the water content of aerosol does not seem to be the main factor influencing the discrepancy between in situ and remote sensing extinctions in the present study. However, we will estimate this effect in a more quantitative approach when comparing in situ and sun photometer retrievals of the aerosol PSD.

\subsection{Particle size distribution}

\subsubsection{Atmospheric structure filters application}

The in situ volume PSDs (SMPS and OPC) were compared to the volume PSDs retrieved from the sun photometer measurements for both coarse and fine modes. The comparison with the totality of the sun photometer and in situ PSD parameters regardless of the situation of the PUY station in the FT or ML can be found in the Appendix (Fig. A1). The in situ fine mode diameters are clearly higher (by $72 \%$ for the majority of cases) than the diameters retrieved with the sun photometer for all seasons, while the in situ concentrations are mainly lower than the concentrations retrieved from the sun photometer, in agreement with the extinction measurement comparison (Fig. 4). Previous works show some impact of sampling techniques on the modal standard deviation (Osborne and Haywood, 2005), leading to higher integrated concentrations from sun photometer measurements. In this particular work, the distance between the two sites is short enough to limit horizontal inhomogeneities. As evidenced by 


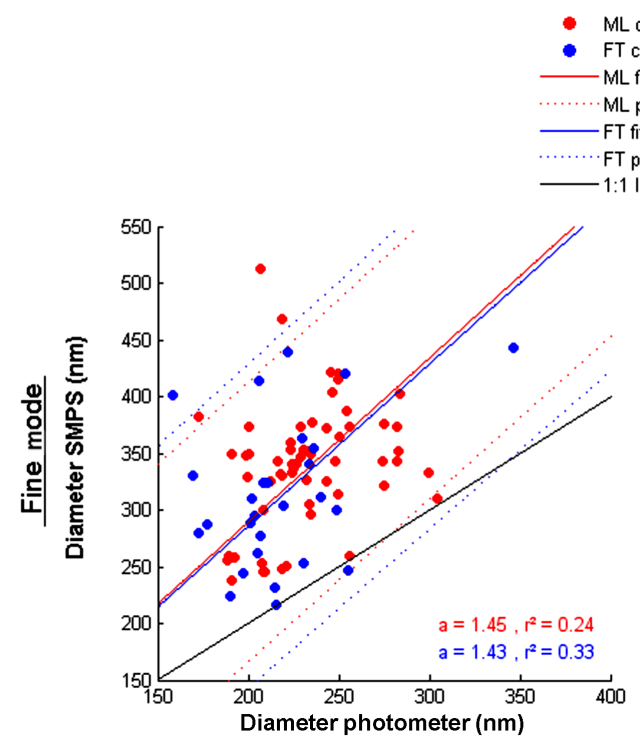

- ML cases

FT cases

ML prediction bounds

FT fitted curve

... FT prediction bounds
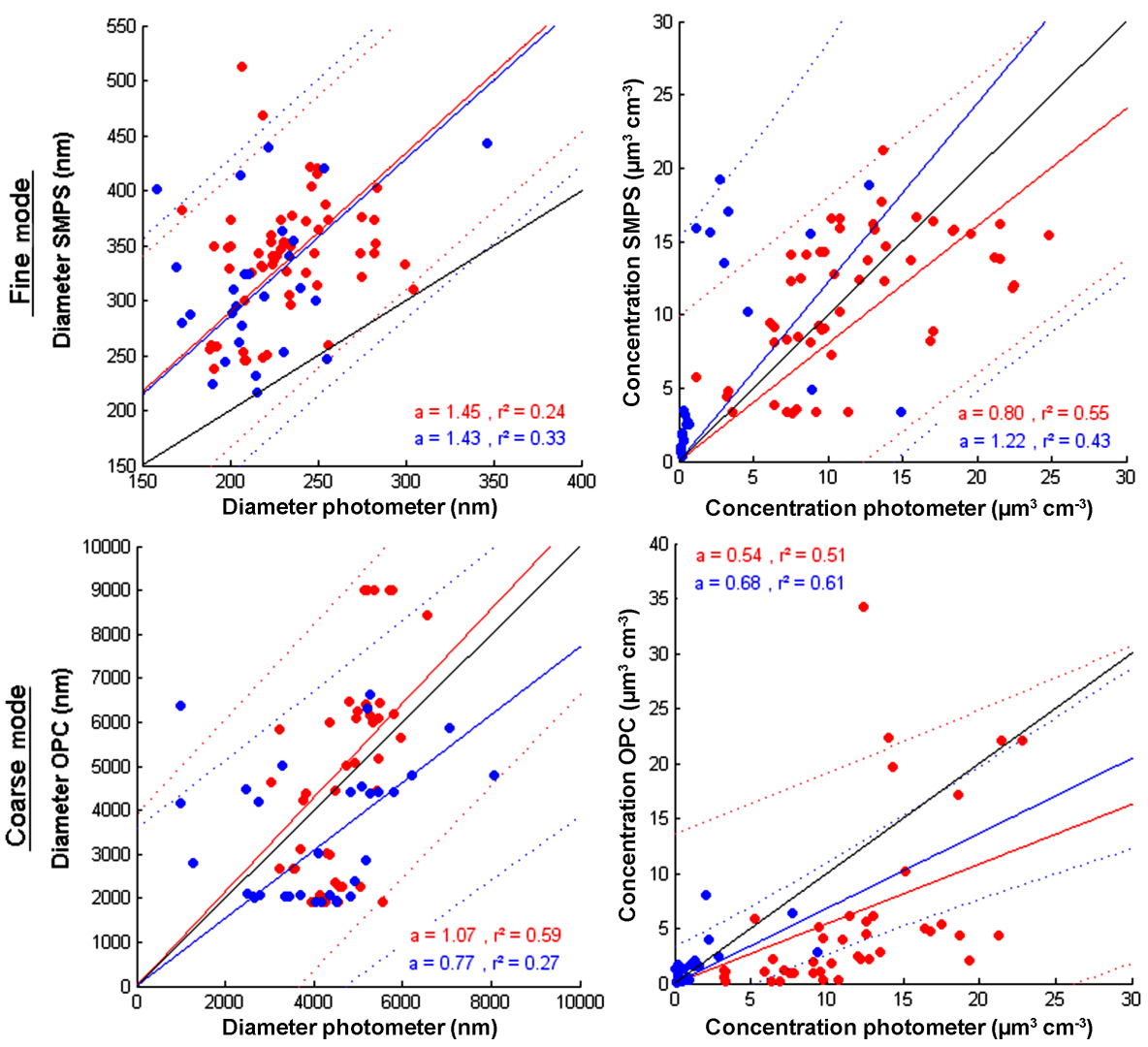

Figure 7. Scatter plot of fine and coarse mode modal diameters, and volume concentrations after applying the ML and FT contribution factors to sun photometer concentrations. Blue fit and markers are for FT data and red fit and markers for ML data.

the comparisons of extinction coefficients, the PSD parameter comparison can also be biased by the fact that the in situ data are for some periods representative of the FT only, while the sun photometer inversion takes the whole column into account. Figure 7 shows results of the comparison between in situ and sun photometer inversion parameters only for homogeneous cases, when in situ data points are segregated into the ML and FT, and the corresponding layer heights are taken into account: concentrations retrieved from the sun photometer were calculated per unit volume of boundary layer for ML cases (divided by the ML height) and of free-tropospheric layer for FT cases divided by (5000 $\mathrm{m}-\mathrm{ML}$ height). There are 73 data points available for fine mode concentrations and 66 points for the coarse mode concentrations. As observed for the extinction, taking into account the segregation between ML and FT and their respective contributions is a main factor influencing the discrepancy between the two measurements techniques.
The average ratio between diameters measured by both techniques is in the range $0.77-1.45$. Overall, in situ diameters in the fine mode are $44 \%$ higher than the diameters retrieved from the sun photometer. Previous detailed analysis of the in situ submicron aerosol size distribution shows that this mode is characterized by two modes, Aitken (diameters between approximately 10 and $100 \mathrm{~nm}$ ) and accumulation (diameters between approximatively 100 and $1000 \mathrm{~nm}$ ) modes (Venzac et al., 2009) that are merged into one single mode during the fitting procedure. Since aerosol scattering is more sensitive to the accumulation mode than to the Aitken mode (Fig. A2), sun photometer retrievals might be biased towards this accumulation mode diameter. As a consequence, sun photometer fine diameters should be overestimated due to the important influence of the accumulation mode compared to the Aitken mode. Because in situ fine mode diameters are already higher than sun photometer fine mode diameters, the bias between the two measurement techniques may even be more important than observed. However, a ver- 
tical gradient of aerosol diameters might explain this feature. Liu et al. (2009) analysed higher effective radii at high altitude than at ground level from an aircraft study above Beijing. Indeed, large aerosols are transported more efficiently over large distances when they are transported at higher wind speeds, which are prevailing at high altitudes. Concerning the coarse mode, in situ diameters are in relatively good agreement with the sun photometer retrievals (slope of 1.07 in the ML and 0.77 in the FT). Coarse mode diameters are better correlated and in better agreement when the PUY station is in the ML than when it is in the FT.

In the ML cases, the in situ aerosol volume concentrations are 80 and $54 \%$ of the sun photometer retrievals for fine and coarse modes respectively (as opposed to in situ extinction being $45 \%$ of the sun photometer extinction). Fine mode volume concentration comparisons are in good agreement with Schmid et al. (2003), reporting airborne in situ extinction between 0 and $4 \mathrm{~km}$ a.s.l., $13 \%$ lower than sun photometer extinction. However, the correlation coefficient in ML conditions is significantly lower $\left(r^{2}<0.60\right)$ for volume concentrations compared to the extinction coefficient analysis $\left(r^{2}=0.79\right)$. This effect may also be partly explained by uncertainties from in situ probes (around 10\%) (Venzac et al., 2009; Burkart et al., 2010) on one hand and uncertainties from sun photometer measurements on the other hand (between 15 and $35 \%$ between 0.1 and $7 \mu \mathrm{m}$ and between 30 and $100 \%$ out of this range) (Dubovik et al., 2000).

In the FT cases, in situ extinction coefficient was 2.26 times higher than sun photometer extinction, while it is $22 \%$ higher and $32 \%$ lower for fine and coarse mode aerosol volume concentrations respectively. Contrary to the ML cases, the correlation observed in the FT cases between volume concentrations increased in comparison to extinction coefficients study $\left(r^{2}=0.43\right.$ and 0.61 for fine and coarse modes respectively as opposed to 0.30 for extinctions comparison). This would indicate that the inversion procedure for retrieving the PSD from sun photometer measurements is relatively reliable when the ML height is low and the sun photometer measurement mainly represents the upper-atmospheric variations (FT cases) but less reliable when the ML is well developed. The fact that the slopes of in situ to sun photometer aerosol volume concentrations are lower than the slopes of the in situ to sun photometer extinction for FT cases indicates a slight overestimation of the aerosol volume concentrations (for both fine and coarse modes) due to the sun photometer retrieval procedure when the ML height is low. On the contrary, the sun photometer retrieval would slightly underestimate the aerosol volume concentrations (for both fine and coarse modes) when the ML is well developed (ML cases).

\subsubsection{Hygroscopicity impact}

In the present section, we will quantify the impact of hygroscopicity on in situ vs. remote sensing comparison. Figure 8 shows volume PSD parameters after in situ PSDs have been corrected for their hygroscopic growth at ambient relative humidities as described in Sect. 3 for both ML and FT cases. The application of the HGF on volume PSD significantly influences the fine mode PSD parameters and a clear increase of diameters and concentrations are observed for high-RH cases $(\mathrm{RH}>50 \%)$. The bias between in situ and remote sensing diameters are about $40 \%$ higher than for the dry cases in the ML and in the FT. For fine mode volume concentrations, the bias between in situ and remote sensing is more than $70 \%$ higher than in dry cases in the FT and in situ volume concentrations became higher (by 20\%) than the sun photometer volume concentrations in the ML. Because the same value of HGF is applied for particles above $420 \mathrm{~nm}$ (see Sect. 3), the effect of humidity on coarse mode PSD parameters is more uncertain. Aerosols may be more hygroscopic than predicted by the parameterization if they are sea salt aerosols or less hygroscopic than predicted if they are Saharan dust (Carrico et al., 2003). However, one can observe that applying a HGF to the coarse mode in situ PSD brings the comparison to $20 \%$ larger in situ than sun photometer diameters for the ML cases and $14 \%$ lower in situ than sun photometer diameters for the FT cases. No significant change is observed for coarse mode volume concentrations. Coarse mode in situ concentrations are in better agreement with the retrieved coarse mode concentrations when the hygroscopic growth is taken into account as well. Moreover, at PUY station, most of coarse mode particles observed are Saharan dusts that are barely hygroscopic.

\section{Conclusion}

The continuous measurements of aerosol properties at the PUY station, $1465 \mathrm{~m}$ a.s.l., in parallel to remote sensing measurements performed at the Cezeaux site, $420 \mathrm{~m}$ a.s.l., allow us to analyse the differences between the two measurement techniques. A 1-year data set of six different instruments operating simultaneously in synergy is used. To our knowledge, it is the first time that such a comparison is realised on a long-term period. The comparison of in situ and sun photometer extinction measurements showed that the PUY station is representative of the total atmospheric column. For all seasons and for all extinction ranges, the two measurement techniques are well correlated. However, an important bias $(86 \%)$ between in situ and sun photometer measurements is observed when the entire sun photometer signal is hypothesised to be confined in the mixed layer (ML) and the multilayer cases are not filtered, especially when the ML height is low. A linear decrease of aerosol extinction with altitude across the whole tropospheric column permits us to obtain a better agreement between the two measurement techniques. Our next step was to test the assumption of two different distinct layers (ML and FT) in which the aerosol concentrations are homogeneously distributed.

The bias is lowered when taking into account the heterogeneity of the atmosphere and the vertical atmospheric struc- 


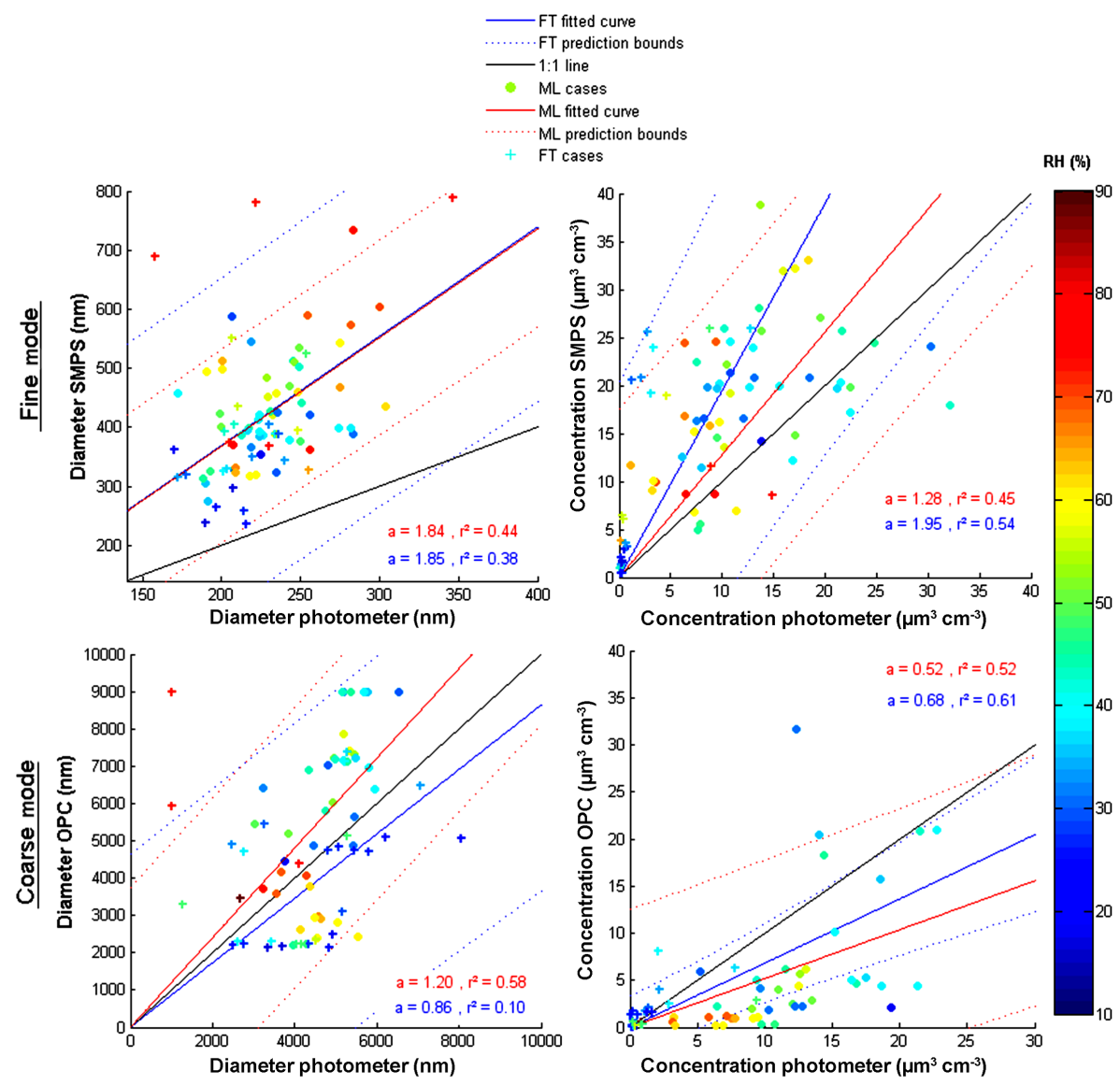

Figure 8. Scatter plot of fine and coarse mode modal diameters, and volume concentrations after applying the humidity growth factor (HGF). Colour corresponds to the mean relative humidity between the two stations. Blue fit and cross markers are for FT data and red fit and circle markers for ML data.

ture to separate ML and FT conditions. Using a combination of lidar (STRAT algorithm) and in situ measurements, the 1year data set was filtered from clouds and high-altitude thin plumes from different sources. This first filter reduces significantly the number of data points (33\% of initial data set for extinction and $30 \%$ for size distributions) and decreases the correlation factor. However, filtering multilayer cases and correcting the sun photometer extinction for either the ML or FT contribution reduces significantly the bias between in situ and sun photometer measurements (from 86 to $55 \%$ for ML cases).

The atmospheric profile model assuming linear decreasing of aerosol concentrations with altitude gives interesting results in the comparison of in situ and remote sensing measurements. Taking into account this decreasing profile up to $5000 \mathrm{~m}$ a.s.l. (thus including both the ML and the FT) leads to the best correlation between extinction coefficients measured by the two techniques. At dry state, the PSD comparison show fine mode diameters $44 \%$ higher from in situ measurements than from sun photometer retrievals and fine mode concentrations $20 \%$ lower and higher for ML and FT cases respectively in agreement with previous studies. In comparison to extinction bias, results permit us to highlight the overestimation of aerosol volume concentrations in FT retrieved by remote sensing techniques for both fine and coarse modes.

The study also focuses on the impact of the humidity on size distributions parameters. An HGF is calculated from a seasonal parameterization in function to the $\mathrm{RH}$ and applied to the in situ particle diameters. In particular, results show an important impact of the humidity on the fine mode of the distribution which increases the bias between the two measurement techniques for diameters. The impact of aerosol hygroscopicity on the extinction coefficient would be an interesting result using a Mie calculation but will need more information on the particle composition.

This long-term study has shown that a ground-based site with in situ aerosol measurements can be representative of the overall atmospheric column and of the regional conditions. Hence, the important number of instruments installed at the mountain station gives us the chance to characterise in a complete view different aerosol layers, taking into account that the extensive aerosol variables (concentration, ex- 
tinction, scattering and absorption coefficients) are likely underestimated compared to the whole ML and overestimated compared to the whole FT. The study also reports an interesting alternative to the use of a linear aerosol vertical decreasing model for the comparison. This study also validates complex remote sensing retrievals such as the PSD, provided that the atmospheric aerosol structure is characterized and aerosol loading is distributed well into the ML and FT. In particular, we show that the hypothesis of the totality of the aerosol loading comprised within the ML would lead to important errors if used in modelling exercises.

\section{Data availability}

Dataset used in this study are available from EBAS database by NILU institut (http://ebas.nilu.no/), AERONET (http://aeronet.gsfc.nasa.gov/) and EARLINET (http://www. earlinet.org) networks. 


\section{Appendix A}

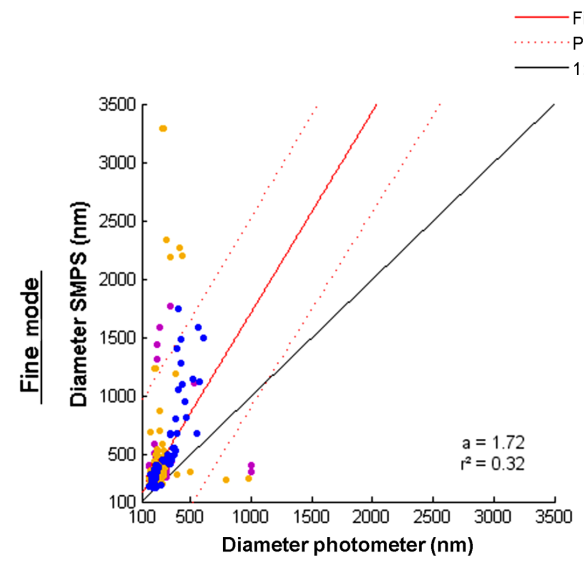

$$
\begin{aligned}
& \text { Fitted curve } \\
& \text { Prediction bounds }
\end{aligned}
$$
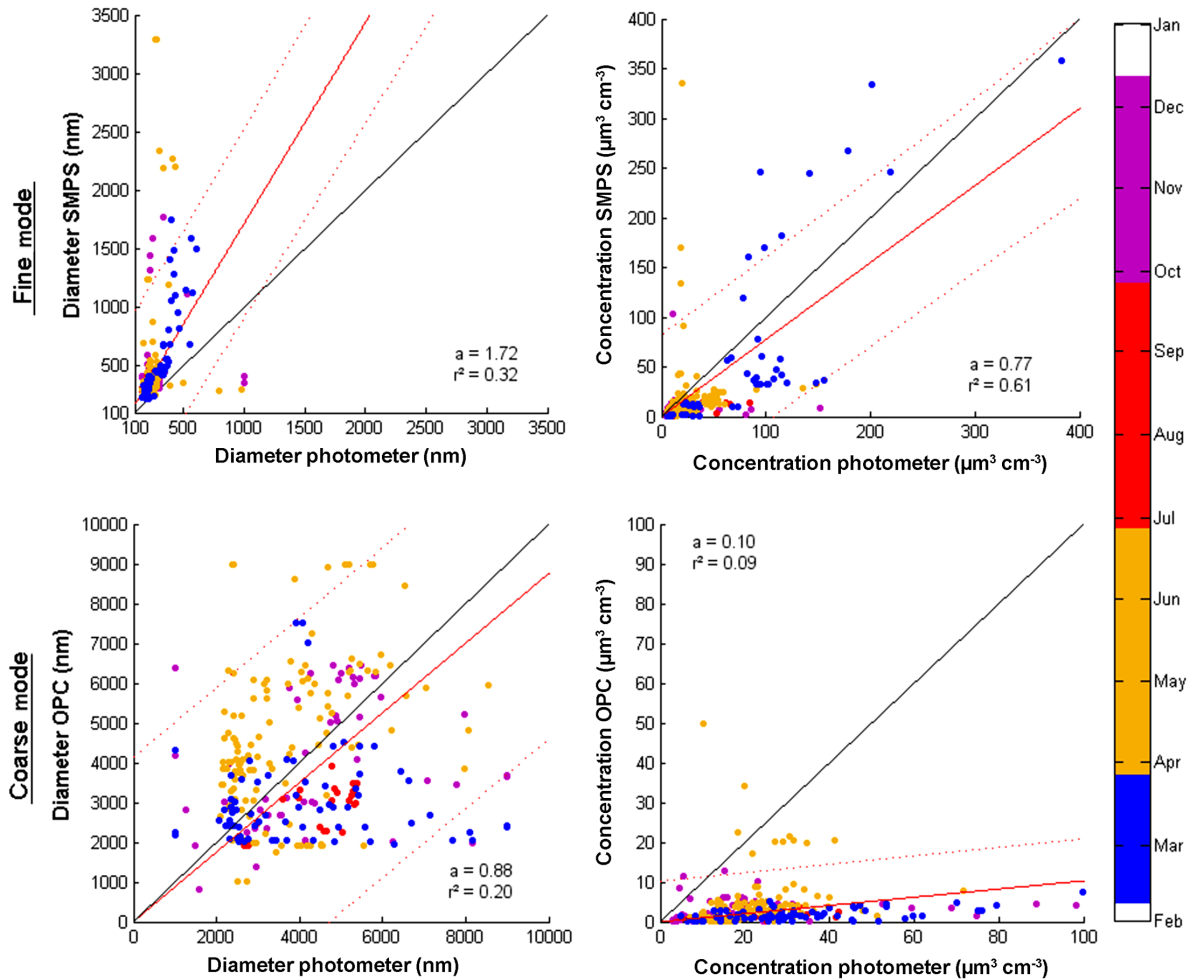

Figure A1. Scatter plots of volume PSD parameters from in situ and sun photometer measurements for both fine (top panels) and coarse (bottom panels) modes in function of season. Left panels represent particle diameters comparison and right panel concentrations. Full red line represents the linear fit and dotted red lines the 5th and 95th percentiles. The black line is the $1: 1$ line.

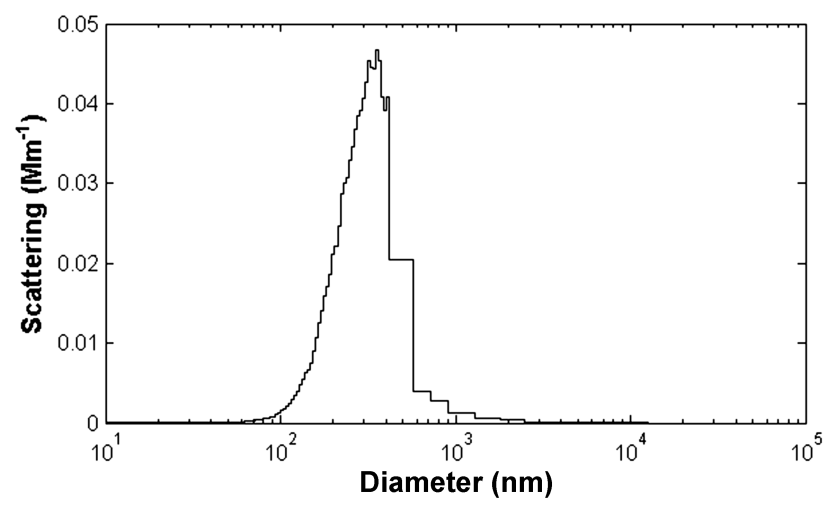

Figure A2. Scattering coefficient from Mie calculation according to each bin of the particle size distribution. 
Acknowledgements. The authors would like to acknowledge the OPGC and its staff and INSU-CNRS for their contribution to establishing and maintaining the PUY measurement site. This work was performed with the financial support of the French ORAURE SOERE, the French national program SNO-CLAP, the European infrastructure projects ACTRIS (grant no. 262254) and ACTRIS-2 (grant no. 654109) and the CNES EECLAT project.

Edited by: A. Kokhanovsky

Reviewed by: three anonymous referees

\section{References}

AERONET: Aerosol Robotic Network, http://aeronet.gsfc.nasa. gov/, last access: September 2016.

Anderson, T. and Ogren, J.: Determining Aerosol Radiative Properties Using the TSI 3563 Integrating Nephelometer, Aerosol Sci. Tech., 29, 57-69, 1998.

Anderson, T. L., Covert, D. S., Marshall, S. F., Laucks, M. L., Charlson, R. J., Waggoner, A. P., Ogren, J. A., Caldow, R., Holm, R. L., Quant, F. R., Sem, G. J., Wiedensohler, A., Ahlquist, N. A. and Bates, T. S.: Performance Characteristics of a High-Sensitivity, Three-Wavelength, Total Scatter/Backscatter Nephelometer, J. Atmos. Ocean. Tech., 13, 967-986, doi:10.1175/15200426(1996)013<0967:PCOAHS>2.0.CO;2, 1996.

Andrews, E., Sheridan, P. J., and Ogren, J. A.: Seasonal differences in the vertical profiles of aerosol optical properties over rural Oklahoma, Atmos. Chem. Phys., 11, 10661-10676, doi:10.5194/acp-11-10661-2011, 2011.

Asmi, A., Wiedensohler, A., Laj, P., Fjaeraa, A.-M., Sellegri, K., Birmili, W., Weingartner, E., Baltensperger, U., Zdimal, V., Zikova, N., Putaud, J.-P., Marinoni, A., Tunved, P., Hansson, H.C., Fiebig, M., Kivekäs, N., Lihavainen, H., Asmi, E., Ulevicius, V., Aalto, P. P., Swietlicki, E., Kristensson, A., Mihalopoulos, N., Kalivitis, N., Kalapov, I., Kiss, G., de Leeuw, G., Henzing, B., Harrison, R. M., Beddows, D., O’Dowd, C., Jennings, S. G., Flentje, H., Weinhold, K., Meinhardt, F., Ries, L., and Kulmala, M.: Number size distributions and seasonality of submicron particles in Europe 2008-2009, Atmos. Chem. Phys., 11, 5505-5538, doi:10.5194/acp-11-5505-2011, 2011.

Baars, H., Ansmann, A., Engelmann, R., and Althausen, D.: Continuous monitoring of the boundary-layer top with lidar, Atmos. Chem. Phys., 8, 7281-7296, doi:10.5194/acp-8-7281-2008, 2008.

Bergin, M. H., Schwartz, S. E., Halthore, R. N., Ogren, J. A., and Hlavka, D. L.: Comparison of aerosol optical depth inferred from surface measurements with that determined by Sun photometry for cloud-free conditions at a continental U.S. site, J. Geophys. Res.-Atmos., 105, 6807-6816, doi:10.1029/1999JD900454, 2000.

Bond, T. C., Covert, D. S., and Müller, T.: Truncation and Angular-Scattering Corrections for Absorbing Aerosol in the TSI 3563 Nephelometer, Aerosol Sci. Tech., 43, 866-871, doi:10.1080/02786820902998373, 2009.

Boucher, O. and Anderson, T. L.: General circulation model assessment of the sensitivity of direct climate forcing by anthropogenic sulfate aerosols to aerosol size and chemistry, J. Geophys. Res.Atmos., 100, 26117-26134, doi:10.1029/95JD02531, 1995.
Bourcier, L., Masson, O., Laj, P., Pichon, J. M., Paulat, P., Freney, E., and Sellegri, K.: Comparative trends and seasonal variation of $7 \mathrm{Be}, 210 \mathrm{~Pb}$ and $137 \mathrm{Cs}$ at two altitude sites in the central part of France, J. Environ. Radioactiv., 102, 294-301, 2011.

Boyouk, N., Léon, J.-F., Delbarre, H., Podvin, T., and Deroo, C.: Impact of the mixing boundary layer on the relationship between PM2.5 and aerosol optical thickness, Atmos. Environ., 44, 271277, doi:10.1016/j.atmosenv.2009.06.053, 2010.

Brooks, I. M.: Finding boundary layer top: Application of a wavelet covariance transform to lidar backscatter profiles, J. Atmos. Ocean. Tech., 20, 1092-1105, 2003.

Burkart, J., Steiner, G., Reischl, G., Moshammer, H., Neuberger, M., and Hitzenberger, R.: Characterizing the performance of two optical particle counters (Grimm OPC1.108 and OPC1.109) under urban aerosol conditions, J. Aerosol Sci., 41, 953-962, doi:10.1016/j.jaerosci.2010.07.007, 2010.

Carrico, C. M., Kus, P., Rood, M. J., Quinn, P. K., and Bates, T. S.: Mixtures of pollution, dust, sea salt, and volcanic aerosol during ACE-Asia: Radiative properties as a function of relative humidity, J. Geophys. Res.-Atmos., 108, 8650, doi:10.1029/2003JD003405, 2003.

Dubovik, O. and King, M. D.: A flexible inversion algorithm for retrieval of aerosol optical properties from Sun and sky radiance measurements, J. Geophys. Res.-Atmos., 105, 20673-20696, 2000.

Dubovik, O., Smirnov, A., Holben, B. N., King, M. D., Kaufman, Y. J., Eck, T. F., and Slutsker, I.: Accuracy assessments of aerosol optical properties retrieved from Aerosol Robotic Network (AERONET) Sun and sky radiance measurements, J. Geophys. Res., 105, 9791-9806, doi:10.1029/2000JD900040, 2000.

EARLINET: A European Aerosol Research Lidar Network to Establish an Aerosol Climatology, http://www.earlinet.org, last access: September 2016.

Ferrare, R., Feingold, G., Ghan, S., Ogren, J., Schmid, B., Schwartz, S. E., and Sheridan, P.: Preface to special section: Atmospheric Radiation Measurement Program May 2003 Intensive Operations Period examining aerosol properties and radiative influences, J. Geophys. Res.-Atmos., 111, D05S01, doi:10.1029/2005JD006908, 2006.

Freville, P., Montoux, N., Baray, J.-L., Chauvigné, A., Réveret, F., Hervo, M., Dionisi, D., Payen, G., and Sellegri, K.: LIDAR Developments at Clermont-Ferrand - France for Atmospheric Observation, Sensors, 15, 3041-3069, 2015.

Haywood, J., Francis, P., Dubovik, O., Glew, M., and Holben, B.: Comparison of aerosol size distributions, radiative properties, and optical depths determined by aircraft observations and Sun photometers during SAFARI 2000, J. Geophys. Res., 108, 8471, doi:10.1029/2002JD002250, 2003.

Henne, S., Brunner, D., Folini, D., Solberg, S., Klausen, J., and Buchmann, B.: Assessment of parameters describing representativeness of air quality in-situ measurement sites, Atmos. Chem. Phys., 10, 3561-3581, doi:10.5194/acp-10-3561-2010, 2010.

Hervo, M., Quennehen, B., Kristiansen, N. I., Boulon, J., Stohl, A., Fréville, P., Pichon, J.-M., Picard, D., Labazuy, P., Gouhier, M., Roger, J.-C., Colomb, A., Schwarzenboeck, A., and Sellegri, K.: Physical and optical properties of 2010 Eyjafjallajökull volcanic eruption aerosol: ground-based, Lidar and airborne measurements in France, Atmos. Chem. Phys., 12, 17211736, doi:10.5194/acp-12-1721-2012, 2012. 
Hervo, M., Sellegri, K., Pichon, J. M., Roger, J. C., and Laj, P.: Long term measurements of optical properties and their hygroscopic enhancement, Atmos. Chem. Phys. Discuss., 14, 27731-27767, doi:10.5194/acpd-14-27731-2014, 2014.

Holben, B. N., Eck, T. F., Slutsker, I., Tanré, D., Buis, J. P., Setzer, A., Vermote, E., Reagan, J. A., Kaufman, Y. J., Nakajima, T., Lavenu, F., Jankowiak, I., and Smirnov, A.: AERONET - A Federated Instrument Network and Data Archive for Aerosol Characterization, Remote Sens. Environ., 66, 1-16, doi:10.1016/S0034-4257(98)00031-5, 1998.

Holmgren, H., Sellegri, K., Hervo, M., Rose, C., Freney, E., Villani, P., and Laj, P.: Hygroscopic properties and mixing state of aerosol measured at the high-altitude site Puy de Dôme (1465 m a.s.1.), France, Atmos. Chem. Phys., 14, 9537-9554, doi:10.5194/acp-14-9537-2014, 2014

IPCC: IPCC (AR5): Climate Change 2013: The Physical Science Basis, Summary for policymakers, Contributionn of Working Group I to the Fifth Assesment report, 2013.

Johnson, B. T., Heese, B., McFarlane, S. A., Chazette, P., Jones, A., and Bellouin, N.: Vertical distribution and radiative effects of mineral dust and biomass burning aerosol over West Africa during DABEX, J. Geophys. Res.-Atmos., 113, D00C12, doi:10.1029/2008JD009848, 2008.

Kanitz, T., Ansmann, A., Engelmann, R., and Althausen, D.: NorthSouth Cross Sections of the Vertical Aerosol Distribution over the Atlantic Ocean from Multiwavelength Raman/polarization Lidar during Polarstern Cruises, J. Geophys. Res.-Atmos., 118, 2643-2655, doi:10.1002/jgrd.50273, 2013.

Kaufman, Y. J. and Holben, B. N.: Hemispherical backscattering by biomass burning and sulfate particles derived from sky measurements, J. Geophys. Res.-Atmos., 101, 19433-19445, doi:10.1029/95JD02532, 1996.

Klett, J. D.: Lidar inversion with variable backscatter extinction ratios, Appl. Optics, 24, 1638-1643, 1985.

Kuze, H., Kinjo, H., Sakurada, Y., and Takeuchi, N.: Fieldof-View Dependence of Lidar Signals by Use of Newtonian and Cassegrainian Telescopes, Appl. Optics, 37, 3128-3132, doi:10.1364/AO.37.003128, 1998.

Laj, P., Klausen, J., Bilde, M., Plaß-Duelmer, C., Pappalardo, G., Clerbaux, C., Baltensperger, U., Hjorth, J., Simpson, D., Reimann, S., Coheur, P. F., Richter, A., De Mazière, M., Rudich, Y., McFiggans, G., Torseth, K., Wiedensohler, A., Morin, S., Schulz, M., Allan, J. D., Attié, J. L., Barnes, I., Birmili, W., Cammas, J. P., Dommen, J., Dorn, H. P., Fowler, D., Fuzzi, S., Glasius, M., Granier, C., Hermann, M., Isaksen, I. S. A., Kinne, S., Koren, I., Madonna, F., Maione, M., Massling, A., Moehler, O., Mona, L., Monks, P. S., Müller, D., Müller, T., Orphal, J., Peuch, V. H., Stratmann, F., Tanré, D., Tyndall, G., Abo Riziq, A., Van Roozendael, M., Villani, P., Wehner, B., Wex, H., and Zardini, A. A.: Measuring atmospheric composition change, Atmos. Environ., 43, 5351-5414, doi:10.1016/j.atmosenv.2009.08.020, 2009.

Liu, P., Zhao, C., Zhang, Q., Deng, Z., Huang, M., Ma, X., and Tie, X.: Aircraft study of aerosol vertical distributions over Beijing and their optical properties, Tellus B, 61, 756-767, doi:10.1111/j.1600-0889.2009.00440.x, 2009.

Magi, B. I., Fu, Q., and Redemann, J.: A methodology to retrieve self-consistent aerosol optical properties using common aircraft measurements, J. Geophys. Res.-Atmos., 112, D24S12, doi:10.1029/2006JD008312 2007.
Molero, F., Sicard, M., Guzman, F. N., Preißler, J., Amodeo, A., Freudenthaler, V., Fernandez, A. J., Tomas, S., Granados, M. J., Wagner, F., Giunta, A., Mattis, I., Pujadas, M., Comeron, A., Alados-Arboledas, L., Guerrero-Rascado, J. L., D’Amico, G., Lange, D., Bravo, J. A., Kumar, D., Pappalardo, G., Giner, J., Muñoz, C., and Rocadenbosch, F.: Study on aerosol properties over Madrid (Spain) by multiple instrumentation during SPALI10 lidar campaign, Opt. Pura Apl., 45, 405-413, 2012.

Morille, Y., Haeffelin, M., Drobinski, P., and Pelon, J.: STRAT: An Automated Algorithm to Retrieve the Vertical Structure of the Atmosphere from Single-Channel Lidar Data, J. Atmos. Ocean. Tech., 24, 761-775, doi:10.1175/JTECH2008.1, 2007.

Müller, D., Ansmann, A., Mattis, I., Tesche, M., Wandinger, U., Althausen, D., and Pisani, G.: Aerosol-type-dependent lidar ratios observed with Raman lidar, J. Geophys. Res.-Atmos., 112, D16202, doi:10.1029/2006JD008292, 2007.

Müller, D., Lee, K.-H., Gasteiger, J., Tesche, M., Weinzierl, B., Kandler, K., Müller, T., Toledano, C., Otto, S., Althausen, D., and Ansmann, A.: Comparison of optical and microphysical properties of pure Saharan mineral dust observed with AERONET Sun photometer, Raman lidar, and in situ instruments during SAMUM 2006, J. Geophys. Res.-Atmos., 117, D07211, doi:10.1029/2011JD016825, 2012.

Nemesure, S., Wagener, R., and Schwartz, S. E.: Direct shortwave forcing of climate by the anthropogenic sulfate aerosol: Sensitivity to particle size, composition, and relative humidity, J. Geophys. Res., 100, 26-105, 1995.

Nicolas, J., Mallet, M., Roberts, G., Denjean, C., Formenti, P., Fresney, E., Sellegri, K., Borgniez, G., Bourrianne, T., Piguet, B., Torres, B., Dubuisson, P., and Dulac, F.: Aerosol direct radiative forcing at a regional scale over the western Mediterranean in summer within the ADRIMED project: airborne observations compared to GAME simulations, Atmos. Chem. Phys. Discuss., in preparation, 2016.

NILU Institut: EBAS database, http://ebas.nilu.no/, last access: September 2016.

Osborne, S. R. and Haywood, J. M.: Aircraft observations of the microphysical and optical properties of major aerosol species, Atmos. Res., 73, 173-201, 2005.

Osborne, S. R., Johnson, B. T., Haywood, J. M., Baran, A. J., Harrison, M. A. J., and McConnell, C. L.: Physical and optical properties of mineral dust aerosol during the Dust and Biomassburning Experiment, J. Geophys. Res.-Atmos., 113, D00C03, doi:10.1029/2007JD009551, 2008.

Petzold, A. and Schönlinner, M.: Multi-angle absorption photometry-a new method for the measurement of aerosol light absorption and atmospheric black carbon, J. Aerosol Sci., 35, 421-441, doi:10.1016/j.jaerosci.2003.09.005, 2004.

Pilinis, C. and Li, X.: Particle shape and internal inhomogeneity effects on the optical properties of tropospheric aerosols of relevance to climate forcing, J. Geophys. Res.-Atmos., 103, 3789 3800, doi:10.1029/97JD02792, 1998.

Pilinis, C., Pandis, S. N., and Seinfeld, J. H.: Sensitivity of direct climate forcing by atmospheric aerosols to aerosol size and composition, J. Geophys. Res., 100, 18739-18754, doi:10.1029/95JD02119, 1995.

Ricchiazzi, P., Gautier, C., Ogren, J. A., and Schmid, B.: A comparison of aerosol optical properties obtained from in situ measurements and retrieved from Sun and sky radiance 
observations during the May 2003 ARM Aerosol Intensive Observation Period, J. Geophys. Res.-Atmos., 111, D05S06, doi:10.1029/2005JD005863, 2006.

Rose, C., Boulon, J., Hervo, M., Holmgren, H., Asmi, E., Ramonet, M., Laj, P., and Sellegri, K.: Long-term observations of cluster ion concentration, sources and sinks in clear sky conditions at the high-altitude site of the Puy de Dôme, France, Atmos. Chem. Phys., 13, 11573-11594, doi:10.5194/acp-13-11573-2013, 2013.

Schmid, B., Hegg, D. A., Wang, J., Bates, D., Redemann, J., Russell, P. B., Livingston, J. M., Jonsson, H. H., Welton, E. J., Seinfeld, J. H., Flagan, R. C., Covert, D. S., Dubovik, O., and Jefferson, A.: Column closure studies of lower tropospheric aerosol and water vapor during ACE-Asia using airborne Sun photometer and airborne in situ and ship-based lidar measurements, J. Geophys. Res.-Atmos., 108, 8656, doi:10.1029/2002JD003361, 2003.

Schmid, B., Ferrare, R., Flynn, C., Elleman, R., Covert, D., Strawa, A., Welton, E., Turner, D., Jonsson, H., Redemann, J., Eilers, J., Ricci, K., Hallar, A. G., Clayton, M., Michalsky, J., Smirnov, A., Holben, B., and Barnard, J.: How well do state-of-the-art techniques measuring the vertical profile of tropospheric aerosol extinction compare?, J. Geophys. Res.-Atmos., 111, D05S07, doi:10.1029/2005JD005837, 2006.

Schmid, B., Flynn, C. J., Newsom, R. K., Turner, D. D., Ferrare, R. A., Clayton, M. F., Andrews, E., Ogren, J. A., Johnson, R. R., Russell, P. B., Gore, W. J., and Dominguez, R.: Validation of aerosol extinction and water vapor profiles from routine Atmospheric Radiation Measurement Program Climate Research Facility measurements, J. Geophys. Res.-Atmos., 114, D22207, doi:10.1029/2009JD012682, 2009.
Seidel, D. J., Ao, C. O., and Li, K.: Estimating climatological planetary boundary layer heights from radiosonde observations: Comparison of methods and uncertainty analysis, J. Geophys. Res.Atmos., 115, D16113, doi:10.1029/2009JD013680, 2010.

Sheridan, P. J., Andrews, E., Ogren, J. A., Tackett, J. L., and Winker, D. M.: Vertical profiles of aerosol optical properties over central Illinois and comparison with surface and satellite measurements, Atmos. Chem. Phys., 12, 11695-11721, doi:10.5194/acp12-11695-2012, 2012.

Venzac, H., Sellegri, K., Villani, P., Picard, D., and Laj, P.: Seasonal variation of aerosol size distributions in the free troposphere and residual layer at the puy de Dôme station, France, Atmos. Chem. Phys., 9, 1465-1478, doi:10.5194/acp-9-1465-2009, 2009.

Wagner, N. L., Brock, C. A., Angevine, W. M., Beyersdorf, A., Campuzano-Jost, P., Day, D., de Gouw, J. A., Diskin, G. S., Gordon, T. D., Graus, M. G., Holloway, J. S., Huey, G., Jimenez, J. L., Lack, D. A., Liao, J., Liu, X., Markovic, M. Z., Middlebrook, A. M., Mikoviny, T., Peischl, J., Perring, A. E., Richardson, M. S., Ryerson, T. B., Schwarz, J. P., Warneke, C., Welti, A., Wisthaler, A., Ziemba, L. D., and Murphy, D. M.: In situ vertical profiles of aerosol extinction, mass, and composition over the southeast United States during SENEX and SEAC ${ }^{4}$ RS: observations of a modest aerosol enhancement aloft, Atmos. Chem. Phys., 15, 7085-7102, doi:10.5194/acp-15-7085-2015, 2015.

Wang, S. C. and Flagan, R. C.: Scanning electrical mobility spectrometer, Aerosol Sci. Tech., 13, 230-240, 1990. 